Available online on 15.09.2020 at http://jddtonline.info
Open Access to Pharmacentical and Medical Research
undestricted non-commercial use, provided the original work is properly cited

Open $\odot$ Access

Research Article

\title{
Antituberculosis: Synthesis and theoretical study of New Schiff base ligand; 2,2'-\{(5-amino-1,3-phenylene) bis[nitrilo(E)methylylidene]\}dibenzene-1,4- diol
}

\author{
Salim Madani ${ }^{1,2 *}$, Kamel Mokhnache ${ }^{1,3}$, Noureddine Charef ${ }^{1}$ \\ ${ }^{1}$ Laboratory of Applied Biochemistry, Department of Biochemistry, Faculty of Natural and Life Sciences, University Ferhat Abbas, Setif-1- \\ 19000 Algeria \\ 2 Department of chemistry, Faculty of Sciences, University Ferhat Abbas, Setif-1, 19000 Algeria \\ ${ }^{3}$ Department of Process Engineering, Faculty of Technology, University Hassiba Benbouali, Chlef, 02000 Algeria
}

\begin{abstract}
The ability to breathe and generate adenosine triphosphate is necessary to the persistence, physiology and pathogenesis of Mycobacterium tuberculosis that causes TuB. By doing a theoretical study of a chemical compound, Schiff Base 2,2'-\{(5-amino-1,3-phenylene) bis[nitrilo(E)methylylidene]\}dibenzene-1,4-diol, where almost all biological activities have been studied theoretically exploiting a computer software PASS (Prediction of Activity Spectra for Substance) for enhancing Computer Aided Drug Designing, as well as studying the class of toxicity in the human body by GUSAR software, which showed biological activity against the tuberculosis epidemic that killed many people, and a protocol was proposed for prepared and study of the properties of this compound.
\end{abstract}

Keywords: GUSAR software, Synthesis, Schiff base, Tuberculosis, Toxicity, PASS prediction.

Article Info: Received 11 July 2020; Review Completed 14 August 2020; Accepted 19 August 2020; Available online 15 September 2020

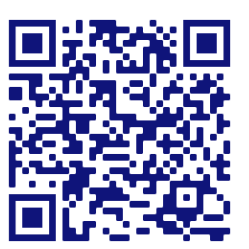

Cite this article as:

Madani S, Mokhnache K, Charef N, Antituberculosis: Synthesis and theoretical study of New Schiff base ligand; 2,2'-\{(5amino-1,3-phenylene) bis[nitrilo(E)methylylidene]\} dibenzene-1,4-diol, Journal of Drug Delivery and Therapeutics. 2020; 10(5):82-85 http://dx.doi.org/10.22270/jddt.v10i5.4360

*Address for Correspondence:

Salim Madani, Laboratory of Applied Biochemistry, Department of Biochemistry, Faculty of Natural and Life Sciences, Univer sity Ferhat Abbas, Setif-1- 19000 Algeria

\section{INTRODUCTION}

Among the deadliest infectious diseases is tuberculosis. ${ }^{1}$ In 2018, according to the census of the world organization approximation of 10.5 million people are contaminated by tuberculosis (TuB) worldwide. Including 5.7 million Men, 3.2 million Women and 1.1 million Children, whereas 1.5 million deaths due to this disease worldwide ${ }^{2}$. (TuB) is classified as an infectious epidemic caused by various types of mycobacteria, collectively called tubercle bacilli ${ }^{3}$, including M. bovis, Mycobacterium tuberculosis, M. caprae, M. africanum, M. canettii, M. microti, and M. pinnipedii. It usually affects the lung (called pulmonary TuB) and has the ability to affect other organs (called extrapulmonary TuB) 4 The disease has witnessed a spread widely in the last half century, followed by many and varied changes in economic, medical and even social factors, in addition to disease resistance to the same existing drugs. Although in recent years the research that explored effective drug doses and combinations for tuberculosis (TuB) treatment has expanded greatly, this led to a decrease in the death rate for (tub) by $22 \%$ last twenty years, yet the inevitable threats arising from resistant and persistent (TuB) are a serious concern 2,5 . With the limited availability of anti-TuB drugs, whether natural or synthetic, the global burden of this epidemic remains looming on the horizon, with great losses in the rates of patients and deaths 6. Therefore, the desired goal of treatment for tuberculosis is to develop and to create new drugs that are more effective, more affordable, and more easily produced 7,8 . Now one of the most serious public health concerns around the world is the resurgence of (TuB). Despite its global risks to health, tuberculos is a non-priority disease, and no new TB treatments have been discovered on the market over the past 50 years, since the discovery of the drug with a new mechanism of action (rifampicin) in 1963 . The complexity of the structure and characteristics of the mycobacterial cell wall, the lengthy treatment duration, multi-resistance and extensive drug resistance developed by the pathogen favors the recurrence of the infection and thus making difficult to treat the disease clinically 10 . About 50 
years ago, a significant decrease in desease cases was observed worldwide due to the introduction of fist-line drugs such as adenosine triphosphate (ATP) and promises to breathe through the electron transport chain (ETC) and (Schiff bases) as compounds of new importance to the drug. Because it has many interesting properties and wide applications in the pharmaceutical, medical, material and agricultural sciences, Schiff base are given great interest 11-14. It choosed because of the imine function in its structure which is highly effective in biological activities 15,16. the Schiff base was first prepared by the researcher Hugo Schiff in $1864{ }^{17}$. They can be considered a sub-class of imines The term is often synonymous with azomethine, synthesized by reaction between aliphatic or aromatic amine and a carbonyl compound by nucleophilic addition to generate an imine group18. The compounds of Schiff bases have been classified for their active biological activities such as antioxidant 19 , antimicrobial ${ }^{20}$, antifungal 21 , antibacterial 22 , anticonvulsant 23 , anticancer 24 , antineoplastic 25 , antiinflammatory 26, antiproliferative 27 and antituberculosic and so on ${ }^{28}$. Since the discovery of the Schiff bases, they have been manufactured on a large scale for industrial use and pharmacological properties and this is due to the importance of their medical assays as antioxidant, antitumor and bacterial purposes. However, the biological activity of these compounds mainly the antituberculosic activity deserves further research. This paper reviews a theoretical study of Schiff bases on antituberculosic activity and its toxicity level, and highlights the most effective activity of this compound, especially as an anti-TuB bacterium.

\section{EXPERIMENTAL}

Scheme.1 shows the preparation procedures of the $2,2^{\prime}-\{(5-$ amino-1,3-phenylene)bis[nitrilo

(E)methylylidene]\}dibenzene-1,4-diol. By reaction of the benzene-1,3,5-triamine and 2,5-dihydroxybenzaldehyde in refluxing methanol the Schiff base ligand was prepared. After evaporating the solvents, the precipitates were filtered off and dried in air ${ }^{29}$.<smiles>Nc1cc(N)cc(N)c1</smiles><smiles>COO</smiles>

Scheme 1: Reaction of benzene-1,3,5-triamine with 2,5-dihydroxybenzaldehyde to produce the Schiff base.

Table 1: Predicted activity of synthesized compound 2,2'-\{(5-amino-1,3-phenylene)bis [nitrilo(E)methylylidene] $\}$ dibenzene1,4-diol by PASS:

\begin{tabular}{|c|c|c|c|c|c|}
\hline \multirow[t]{2}{*}{ Predicted Activity } & \multicolumn{2}{|c|}{$\begin{array}{l}\text { Synthesized } \\
\text { compound }\end{array}$} & \multirow[t]{2}{*}{ Predicted Activity } & \multicolumn{2}{|c|}{$\begin{array}{l}\text { Synthesized } \\
\text { compound }\end{array}$} \\
\hline & $\mathbf{P a}$ & $\overline{P_{i}}$ & & $\mathbf{P a}$ & $\overline{P_{i}}$ \\
\hline Antituberculosic & 0,737 & 0,004 & Antihypoxic & 0,315 & 0,143 \\
\hline Laccase inhibitor & 0,808 & 0,004 & Antifibrinolytic & 0,233 & 0,065 \\
\hline $\begin{array}{l}\text { Phosphatidylserine } \\
\text { decarboxylase inhibitor }\end{array}$ & 0,722 & 0,010 & Antiviral (Herpes) & 0,277 & 0,108 \\
\hline Antimycobacterial & 0,707 & 0,005 & Antispirochetal & 0,185 & 0,029 \\
\hline Peroxidase inhibitor & 0,711 & 0,011 & Antihypotensive & 0,202 & 0,055 \\
\hline Antiinfective & 0,627 & 0,011 & Antiviral (Trachoma) & 0,155 & 0,017 \\
\hline Antiseborrheic & 0,648 & 0,047 & Antioxidant & 0,194 & 0,058 \\
\hline Antiseptic & 0,583 & 0,008 & Antibiotic & 0,170 & 0,038 \\
\hline Antineoplastic (breast cancer) & 0,545 & 0,015 & Antidote & 0,217 & 0,089 \\
\hline Antiprotozoal (Coccidial) & 0,523 & 0,005 & Antineoplastic (melanoma) & 0,185 & 0,064 \\
\hline Antiparasitic & 0,520 & 0,014 & Antipsoriatic & 0,235 & 0,113 \\
\hline Antiviral (Picornavirus) & 0,540 & 0,035 & Antihemorrhagic & 0,155 & 0,047 \\
\hline $\begin{array}{l}\text { Antineoplastic (colorectal } \\
\text { cancer) }\end{array}$ & 0,465 & 0,015 & Antiinflammatory, ophthalmic & 0,259 & 0,155 \\
\hline Antineoplastic (colon cancer) & 0,457 & 0,015 & Antitoxic & 0,220 & 0,117 \\
\hline Antidyskinetic & 0,495 & 0,065 & Antitreponemal & 0,137 & 0,036 \\
\hline
\end{tabular}




\begin{tabular}{|c|c|c|c|c|c|}
\hline Antihelmintic & 0,434 & 0,013 & Antidiarrheal & 0,196 & 0,098 \\
\hline Antifungal & 0,455 & 0,038 & Antiprotozoal (Plasmodium) & 0,176 & 0,082 \\
\hline Antibacterial & 0,437 & 0,023 & Antiprotozoal (Babesia) & 0,140 & 0,060 \\
\hline Antiprotozoal (Amoeba) & 0,424 & 0,021 & Anticarcinogenic & 0,199 & 0,121 \\
\hline Antineoplastic & 0,477 & 0,079 & Antiprotozoal (Histomonas) & 0,095 & 0,021 \\
\hline Antiviral (Adenovirus) & 0,407 & 0,027 & Antiuremic & 0,163 & 0,106 \\
\hline Antinociceptive & 0,447 & 0,073 & Antithyroid & 0,127 & 0,072 \\
\hline Antiprotozoal (Trypanosoma) & 0,376 & 0,048 & Antineoplastic (uterine cancer) & 0,125 & 0,075 \\
\hline Antiprotozoal (Trichomonas) & 0,331 & 0,016 & Antiperistaltic & 0,181 & 0,132 \\
\hline Antineoplastic (lung cancer) & 0,322 & 0,036 & Antifungal (Pneumocystis) & 0,060 & 0,023 \\
\hline Antiprotozoal & 0,323 & 0,038 & Antidote, heavy metal & 0,084 & 0,050 \\
\hline Antipyretic & 0,306 & 0,043 & Antiviral (Influenza A) & 0,213 & 0,185 \\
\hline Antiprotozoal (Toxoplasma) & 0,283 & 0,020 & Antineoplastic (sarcoma) & 0,155 & 0,143 \\
\hline Antischistosomal & 0,274 & 0,020 & Antibacterial, ophthalmic & 0,125 & 0,114 \\
\hline Antiviral (Poxvirus) & 0,304 & 0,057 & Antidote, organophosphates & 0,022 & 0,022 \\
\hline Antileprosy & 0,262 & 0,018 & Antiviral (Hepatitis B) & 0,159 & 0,159 \\
\hline Antineoplastic (liver cancer) & 0,269 & 0,032 & Antihypoxic & 0,315 & 0,143 \\
\hline Antimyopathies & 0,333 & 0,105 & Antifibrinolytic & 0,233 & 0,065 \\
\hline Antihematotoxic & 0,236 & 0,029 & Antiviral (Herpes) & 0,277 & 0,108 \\
\hline Astringent & 0,219 & 0,013 & Antispirochetal & 0,185 & 0,029 \\
\hline Antirickettsial & 0,229 & 0,026 & Antihypotensive & 0,202 & 0,055 \\
\hline Antineoplastic antimetabolite & 0,225 & 0,029 & Antiviral (Trachoma) & 0,155 & 0,017 \\
\hline Antineoplastic antimetabolite & 0,225 & 0,029 & Antioxidant & 0,194 & 0,058 \\
\hline Antinephritic & 0,288 & 0,106 & Antibiotic & 0,170 & 0,038 \\
\hline Antiviral (CMV) & 0,251 & 0,075 & Antidote & 0,217 & 0,089 \\
\hline Antineoplastic (melanoma) & 0,185 & 0,064 & & & \\
\hline
\end{tabular}

\section{RESULTS}

\section{Acute rat toxicity prediction of Schiff base}

The theoretical study of the acute toxicity and the classification of the toxicity of the schiff base studied by computer approaches allow to give important information before its preparation. In addition, due to the time consuming and high cost of animal models and even the ethical side, theoretical predictions have been used as a surrogate in in vivo toxicological studies. The values of (Intraperitoneal route of administration IP, Intravenous route of administration IV, Oral route of administration and Subcutaneous route of administration SC) and the predicted toxicity class for 2,2 '- $\{(5$-amino-1,3 phenylene ) bis [nitrilo (E) methylylidene]\} dibenzene-1,4-diol were predicted by GUSAR software in rodents. The results show that the compound was classified in the fifth class for subcutaneous administration with a high $\mathrm{LD}_{50}$ value of $1571,000 \mathrm{mg} / \mathrm{kg}$. the same thing noted for the Intraperitoneal and Oral administration routes were classified in the fifth class with $\mathrm{LD}_{50}$ values of 1032,000 and $3681,000 \mathrm{mg} / \mathrm{kg}$, respectively, on the other hand the Intravenous route was classified in the fourth class with an $\mathrm{LD}_{50}$ value of $105,000 \mathrm{mg} / \mathrm{kg}$ (table 2), and that indicates our Schiff base is classified in the nontoxic class.

Table 2: Acute rat toxicity prediction of 2,2'-\{(5-amino-1,3 phenylene)bis[nitrilo (E) methylylidene] $\}$ dibenzene-1,4-diol.

\begin{tabular}{|l|c|c|c|}
\hline Administration route & $\begin{array}{c}\text { LD50 } \\
\mathbf{l o g} \mathbf{( m m o l} / \mathbf{k g})\end{array}$ & $\begin{array}{c}\text { LD50 } \\
\text { (mg/kg) }\end{array}$ & $\begin{array}{c}\text { Predicted } \\
\text { toxicity class }\end{array}$ \\
\hline Intraperitoneal (IP) & 0.453 & 1032.000 & Class 5 \\
\hline Intravenous (IV) & -0.539 & 105.000 & Class 4 \\
\hline Oral administration & 1.006 & 3681.000 & Class 5 \\
\hline Subcutaneous (SC) & 0.636 & 1571.000 & Class 5 \\
\hline
\end{tabular}




\section{CONCLUSION}

in this study we have proposed synthesis of novel 2,2 '-\{(5amino-1,3phenylene)bis[nitrilo(E)methylylidene]\}dibenzene-1,4-diol. By method is maintaining environmental friendly approach for the synthesis of Schiff base, along with their prediction of biological activities using a computer software PASS, which gave a good antituberculosis property against $M$. tuberculosis and their toxicity by GUSAR software which showed weak toxicity. Nevertheless, the anti-TuB activity of this compound requires further research and development, and there is ample scope to explore new promising leads for designing more effective antimycobacterial drugs to counter the classic example of poverty-TuB.

Conflict of Interest: No conflict of interest was declared by the authors in this research article.

\section{ACKNOWLEDGEMENTS}

This work was supported by the Algerian Ministry of Higher Education and Scientific Research (MESRS); The authors wish to express their gratitude and appreciation.

\section{REFERENCES}

[1] Gulland A. World leaders heed Macron's call and pledge, $\$ 14 \mathrm{bn}$ to fight killer diseases. The Telegraph, October 10, 2019.

[2] World Health Organization (WHO), Global tuberculosis report 2019. https://www.who.int/tb/publications/global_report/en/

[3] Satoskar RS; Bhandarkar SD; Ainapure SS. Pharmacology and Pharmacotherapeutics. Mumbai: Popular Prakashan; 2003, 727744.

[4] Dye C; Scheele S; Dolin P; Pathania V; Raviglione MC. Consensus statement. Global burden of tuberculosis: estimated incidence, prevalence, and mortality by country. WHO Global Surveillance and Monitoring Project, JAMA, 1999; 282:677- 686

[5]. World Health Organisation. Global tuberculosis report 2016. 2016. http:// www.who.int/tb/publications/global_report/en/. Accessed 20 Dec 2016.

[6] Gandhi NR; Nunn P; Dheda K; Schaaf HS; Zignol M; Van Soolingen D; Jensen P; Bayona J. Multidrug-resistant and extensively drugresistant tuberculosis: a threat to global control of tuberculosis. Lancet. 2010; 375:1830-1843.

[7] Caleffi-Ferracioli KR, Maltempe FG, Siqueira VLD, Cardoso RF. Fast detection of drug interaction in Mycobacterium tuberculosis by a checkerboard resazurin method. Tuberculosis 2013; 93:660-3.

[8] Sacks LV; Behram RE, Challenges, successes, and hopes in the development of novel TB therapeutics. Future Med Chem. 2009; 1:749-756.

[9] Koul A; Arnoult E; Lounis N; Guillemont J; Andries K. Th challenge of new drug discovery for tuberculosis. Nature, 2011; 7331:483-490.

[10] Ugwu DI; Ezema BE; Eze FU; Ugwuja DI. Synthesis and structural activity relationship study of antitubercular carboxamides. Int J Med Chem , 2014; 2014:1-18.

[11] Cerchiaro G; Aquilano K; Filomeni G; Rotilio G; Cirioio MR; Ferreira A. Isatin Schiff base Copper(II) complexes and their influence on cellular viability. J Inorga Biochem ,2005; 99:14331440.
[12] Vancoa J; Svajlenova 0; Racanskac E; Muselika J; Valentova J. Antitradical activity of different Copper(II) Schiff base complexes and their effect on alloxaninduced diabetes. J Trace Elem Med Biol, 2004; 18:155- 161.

[13] Marcell DF; Thatyana R A V; Erika M C D; Maria C S L; Solange M S V W; James L W; Vitor F F; Marcus V N S. Synthesis and antitubercular activity of novel Schiff bases from D-mannitol. Carbohydr Res, 2009; 12:2042-2047.

[14] Nabel NA; Mohamed FZ. Structural and biological behaviors of some nonionic Schiff base amphiphiles and their $\mathrm{Cu}(\mathrm{II})$ and Fe(III) metal complexes. Colloids Surf. B, 2008; 64:179-183.

[15] Guo Z; Xing R; Liu S; Zhong Z; Ji X; Wang L. Antifungal properties of Schiff bases of chitosan, N-substituted chitosan and quaternized chitosan. Carbohydr Res 2007; 342:1329-1332

[16] Atwood JL; Steed JW. Supramolecular Chemistry. New York: John Wiley \& Sons; 2000.

[17] Zheng Y ; Ma K; Li H ; Li J ; He J ; Sun X ; Li R ; Ma J. One pot synthesis of imines from aromatic nitro compounds with a novel $\mathrm{Ni} / \mathrm{SiO} 2$ magnetic catalyst. Catal Lett 2009; 128:465-474.

[18] Schiff H. Mittheilungen aus dem universita tslaboratorium in Pisa: Eine neue reihe organischer basen. Justus Liebigs Ann Chem 1864; 131:118-119.

[19] Barbuceanu SF; Ilies DC; Saramet G; Uivarosi V; Draghici C; Radulescu V. synthesis and antioxidant activity evaluation of new compounds from hydrazine carbothioamide and 1,2,4triazole class containing diarylsulfone and 2,4- difluorophenyl moieties. Int J Mol Sci 2014; 15:10908-10925.

[20] Pandeya SN; Sriram D; Nath G; Clercq E De. Synthesis, antibacterial, antifungal and antiviral activity evaluation of some new bis-Schiff bases of isatin and their derivatives. Pharm Acta Helv 1999; 74:07-11.

[21] Singh WM; Dash BC. Synthesis of some new Schiff bases containing thiazole and oxazole nuclei and their fungicidal activity. Pesticides 1988; 22: 33-37.

[22] Pandeya SN ; Sriram D ; Nath G ; Clercq E de. Synthesis, antibacterial, antifungal and anti-HIV evaluation of Schiff and Mannich bases of isatin and its derivatives with triazole. Arzneimittel-Forsch 2000; 50:55-59.

[23] Kelley JL; Linn JA; Bankston DD; Burchall CJ; Soroko FE; Cooper BR. 8-Amino-3- benzyl-1,2,4-triazolo[4,3- $\alpha$ ]pyrazines: Synthesis and anticonvulsant activity. J Med Chem 1995; 38: 3676-3679.

[24] Chazin, EL et al. synthesis and biological evaluation of novel 6hydroxybenzo[d] [1,3]oxathiol-2-one Schiff bases as potential anticancer agents. Molecules 2015; 20:1968-1983.

[25] De Souza A0; Galetti FCS; Silva CL; Bicalho B; Parma MM; Fonseca SF. antimycobacterial and cytotoxicity activity of synthetic and natural compounds. Quím Nova 2007; 30:15631566.

[26] Turan Z; Kaplancikli ZA; Ozdemir A; Chevallet P. Studies on 1,2,4-triazole derivatives as potential anti-inflammatory agents. Arch. Pharm Chem Life Sci 2007; 340:586-590.

[27] Tarafder M T H; Kasbollah A; Saravanan N; Crouse K A; Ali A M; Tin Oo K S. methyldithiocarbazate and its Schiff bases: evaluation of bondings and biological properties. J. Biochem. Mol. Biol. Biophys. 2002, 6:85-91.

[28] Aboul-Fadl T; AbdelHamid M F; AbdelSaboor H E. Synthesis, antitubercular activity and pharmacokinetic studies of some Schiff bases derived from 1-alkylisatin and isonicotinic acid hydrazide. Arch Pharm Res, 2003; 26:778-784.

[29] Hans Zengel, Manfred Bergfeld, 1977. benzene-1,3,5-trisacetoxime and the process for making phloroglucnol therewth, (Division of Ser. No. 823,789,). U.S. Patent and Trademark Office. https://patents.google.com/patent/US4157450. 